\title{
Efficacy of Topical Mometasone Furoate 0.1\% Cream in the Treatment of Atopic Dermatitis
}

\author{
Islam MZ1 , Ali $\mathrm{ME}^{2}$, Wahab MA³, Khondker L ${ }^{4}$. Siddique MRU ${ }^{5}$
}

\begin{abstract}
A clinical trial was carried out in the department of Dermatology and Venereology, Bangabandhu Sheikh Mujib Medical University (BSMMU), Dhaka to evaluate the efficacy of Mometasone Furoate $0.1 \%$ cream in atopic dermatitis. Forty patients of atopic dermatitis were selected and randomized into two groups. In Group I, study patients were applied Mometasone Furoate $0.1 \%$ cream to the affected skin and in Group II, control patients were allowed to apply white vaseline to the affected skin. SCORAD index was assessed fortnightly at $2^{\text {nd }}$ and $3^{\text {rd }}$ visit and final SCORAD index were calculated at the end of 4 week ( $3^{\text {rd }}$ visit). In the study, at base line SCORAD index in case group was $49.76 \pm 17.25$ and in control group was $55.25 \pm 13.94$ ( $p>0.05)$. At $2^{\text {nd }}$ visit that is at the end of 2 (two) weeks of medication SCORAD in case group was $27.39 \pm 11.16$ and in control group was $50.05 \pm$ 14.69 ( $p=0.001)$ and at $3^{\text {rd }}$ visit that is at the end of 4 (four) weeks of medication in case group SCORAD was $12.08 \pm$ 6.87 and in control group was $46.70 \pm 14.80(p=0.001)$. Percent of reduction of SCORAD from $1^{\text {st }}$ visit to $3^{\text {rd }}$ visit in case group was $76.70 \pm 8.10$ and in control group was 16.88 $\pm 8.70(p=0.001)$ which indicates satisfactory improvement and statistically significant. It can be concluded that once daily application of mometasone furoate $0.1 \%$ cream is effective in atopic dermatitis.
\end{abstract}

Key words : Efficacy of mometasone furoate $0.1 \%$ cream, treatment of atopic dermatitis.

\section{Introduction}

Atopic dermatitis is an itchy, chronic, or chronically relapsing, inflammatory skin condition. The lesion is characterized by

1. Dr. Md Zafrul Islam

Medical Officer, Department of Dermatology \& Venereology

Bangabandhu Sheikh Mujib Medical University, Dhaka

2. Professor (Dr.) Mohammad Eakub Ali

Department of Dermatology and Venereology

Bangabandhu Sheikh Mujib Medical University, Dhaka

3. Professor (Lt Col) Dr. Md Abdul Wahab (Retd)

Department of Dermatology and Venereology

Bangabandhu Sheikh Mujib Medical University, Dhaka

4. Corresponding Author : Dr. Lubna Khondker Assistant Professor, Dept of Dermatology \& Venereology Bangabandhu Sheikh Mujib Medical University, Dhaka E-mail: lubnaderma@gmail.com

5. Dr. Mohammad Rahmat Ullah Siddique Research Assistant, Department of Dermatology \& Venereology Bangabandhu Sheikh Mujib Medical University, Dhaka itchy papules which become excoriated and lichenified and typically have a flexural distribution. ${ }^{1}$ In 1925 , Coca introduced the concept of atopy, meaning "out of place" or "strange", to signify the hereditary tendency to develop allergies to food and inhalant substances. ${ }^{2}$ Atopic dermatitis is a genetically determined, distinctive eczematous condition that usually occurs in people who have a personal or family history of asthma or seasonal or perennial allergic rhinitis. About $80 \%$ of the patients with atopic dermatitis have increased amount of total IgE. Atopic dermatitis can be classified into three stages: Infantile atopic dermatitis, occurring from 2 months to 2 years of age; childhood atopic dermatitis from 2 to 10 years and adult atopic dermatitis. Pruritus is the hallmark of atopic dermatitis in all stages. ${ }^{2}$ Atopic dermatitis (AD) is a common inflammatory skin disease affecting between $10 \%$ and $20 \%$ of children and $1 \%$ and $3 \%$ of adults. ${ }^{3,4}$ AD causes significant physical, psychological and social distress. The prevalence of $\mathrm{AD}$ has increased steadily over the last 30 years. The disease accounts for $10 \%$ to $20 \%$ of all referral to dermatologists and about $30 \%$ of dermatologic consultations in general practice. ${ }^{5,6}$ At present, there are no $100 \%$ life-long cures for AD. Topical steroids and calcineurin inhibitors are the current standard for topical anti-inflammatory therapy. The local and systemic side effects of topical steroids are well recognized. Local effects include skin atrophy, striae, telangiectasias, hypopigmentation, rosacea, perioral dermatitis and acne. Systemic side effects include adrenal suppression, cataracts, glaucoma and growth retardation in children. ${ }^{5,7}$ Mometasone furoate cream $0.1 \%$ is a medium potency corticosteroid indicated for the relief of the inflammatory and pruritic manifestations of corticosteroidresponsive dermatoses, particularly atopic dermatitis in children. ${ }^{8,9}$ The availability of Mometasone furoate $0.1 \%$ cream and the sequels and morbidity of atopic dermatitis in our patients inspired us to undertake a study to evaluate the efficacy of Mometasone furoate $0.1 \%$ cream in atopic dermatitis patients in Bangladesh.

\section{Materials \& Methods}

A clinical trial was carried out in the Department of Dermatology and Venereology, Bangabandhu Sheikh Mujib Medical University, Dhaka. This study was carried out for a period of six months from October 2008 to April 2009. Atopic dermatitis patients attended in the indoor and outpatient Department of Dermatology and Venereology, Bangabandhu Sheikh Mujib Medical University, Dhaka was the study population. Inclusion criterias were all patients fulfilling the Hanifin-Rajka criteria for diagnosis of atopic dermatitis, patients of both sexes and age 1 year and above. Exclusion criterias were pregnant women and nursing mothers, hypersensitivity to any of the components in the preparation and subjects unwilling to participate in the study. 


\section{Study procedure}

All the patients were given an explanation of the study and informed consent was taken before entry into the study. A total of 40 (Forty) patients (Group I Study, n=20 and Group II control, $\mathrm{n}=20$ ) were enrolled in this study. A detailed history was taken from the patients. In case of female special attention was given regarding menstrual history and use of contraceptives. In all patients physical examinations that are general examinations, systemic examinations and more meticulously dermatological examination were performed. Blood sample for TC, DC, $\mathrm{Hb} \%$, ESR \& Circulating oesinophil and Serum IgE were taken in each patients. SCORAD index was calculated at the baseline ( $1^{\text {st }}$ visit). The study population was divided into two equal groups: Group I \& Group II. Group I (study group) applied a thin film of the study medicine Mometasone Furoate $0.1 \%$ cream to the affected skin areas once daily at night for 4 weeks. Group II (control group) were allowed to apply white Vaseline to the affected skin once daily at night for 4 weeks. Baseline investigations TC, DC, $\mathrm{Hb} \%$, ESR \& Circulating oesinophil and serum IgE were done. All patients were asked to report fortnightly for $2^{\text {nd }}$ and $3^{\text {rd }}$ follow-up visit at the end of 2 (two) and 4 (four) weeks of medications where they are examined and SCORAD were calculated and recorded. All patients were asked to report immediately if any problem develops during the study period. All information's were collected in a pre-designed data sheet and were recorded. Main out come measure was done with SCORAD and statistical analysis was done with SPSS-13. Statistical analyses were done by using appropriate procedure.

\section{Result}

Among the patients, $85.0 \%$ of all patients were of age group $\leq 12$ years and $15.0 \%$ were from age group of $>12$ years. Sixteen $(80.0 \%)$ of cases and fourteen $(70.0 \%)$ of controls were male and $4(20.0 \%)$ cases and $6(30.0 \%)$ controls were female. Among cases presenting complaints were pruritus $(100.0 \%)$, chronic or chronically relapsing dermatitis $(60.0 \%)$, xerosis $(55.0 \%)$, papulation $(95.0 \%)$, excoriation $(80.0 \%)$ and crusting/oozing (25.0\%). Among controls presenting complaints were pruritus $(100.0 \%)$, chronic or chronically relapsing dermatitis $(65.0 \%)$, xerosis $(95.0 \%)$, papulation $(95.0 \%)$, excoriation $(80.0 \%)$ and crusting/ oozing 40.0\%). Among all patients dermatological findings were observed like flexural lichenification or linearity (75.0\%), ichthyosis palmer hyperlinearity or keratosiss pilaris $(5.0 \%)$, tendency toward cutaneous infection $(75.0 \%)$, tendency toward nonspecific hand or foot eczema (15.0\%), cheilitis $(35.0 \%)$, recurrent conjunctivitis $(35.0 \%)$, recurrent conjunctivitis $(45.0 \%)$, Dannie-morgan infra orbital fold $(45.0 \%)$, keratoconous $(25.0 \%)$, orbital darkening $(10.0 \%)$, facial pallor or facial erythema $(30.0 \%)$, pityriasis alba $(50.0 \%)$, anterior neck fold $(35.0 \%)$, itch when sweating $(65.0 \%)$, food intolerance $(20.0 \%)$, course influenced environmental \& emotional factor $(25.0 \%)$. Mean $\operatorname{IgE}$ in group1 and group2 were $601.30 \pm 423.18$ and $658.30 \pm$ 211.84 respectively ( $p=0.593$ ). In group 1 SCORAD index at baseline was $49.76 \pm 17.25$, at $2^{\text {nd }}$ visit $27.39 \pm 11.16$ and at $3^{\text {rd }}$ visit was $12.08 \pm 6.87$. Percent of reduction from $1^{\text {st }}$ visit to $3^{\text {rd }}$ visit was $76.70 \pm 8.10$. In group2 SCORAD index at baseline was $55.25 \pm 13.94$, at $2^{\text {nd }}$ visit $50.05 \pm 14.69$ and at $3^{\text {rd }}$ visit was $46.70 \pm 14.80$. Percent of reduction from $1^{\text {st }}$ visit to $3^{\text {rd }}$ visit was $16.88 \pm 8.70$.

Table I: Distribution of study population by age

\begin{tabular}{cccc}
\hline Age (in year) & \multicolumn{2}{c}{ Study population } & p value* \\
& Case (Group 1) & Control (Group 2) & \\
\hline$\leq 12$ & $17(85.0)$ & $17(85.0)$ & 0.038 \\
$>12$ & $3(15.0)$ & $3(15.0)$ & \\
Total & $\mathbf{2 0 ( 1 0 0 . 0 )}$ & $\mathbf{2 0}(\mathbf{1 0 0 . 0})$ & \\
\hline
\end{tabular}

*Chi-square test was done to measure the level of significance.

Table II: Distribution of study population by sex

\begin{tabular}{cccc}
\hline Sex & \multicolumn{2}{c}{ Study population } & p value* \\
& Case (Group 1) & Control (Group 2) & \\
\hline Male & $16(80.0)$ & $14(70.0)$ & 0.465 \\
Female & $4(20.0)$ & $6(30.0)$ & \\
Total & $\mathbf{2 0 ( 1 0 0 . 0 )}$ & $\mathbf{2 0}(\mathbf{1 0 0 . 0})$ & \\
\hline
\end{tabular}

*Chi-square test was done to measure the level of significance. "Figure within parentheses indicates in percentage.

Table III: Distribution of patients by chief complaints

\begin{tabular}{lccc}
\hline \multicolumn{1}{c}{$\begin{array}{c}\text { Chief } \\
\text { complaints }\end{array}$} & \multicolumn{2}{c}{ Study population } & p value \\
\multicolumn{1}{c}{ Pruritus } & $\mathbf{2 0}(\mathbf{1 0 0 . 0 )}$ & $\mathbf{2 0 ( 1 0 0 . 0 )}$ & $\begin{array}{c}\text { Not } \\
\text { calculated }\end{array}$ \\
\hline $\begin{array}{l}\text { Chronic or } \\
\text { chronically }\end{array}$ & $12(60.0)$ & $13(65.0)$ & $0.744^{*}$ \\
$\begin{array}{l}\text { relapsing } \\
\text { dermatitis }\end{array}$ & & & \\
Xerosis & $11(55.0)$ & $19(95.0)$ & $0.003^{*}$ \\
Papulation & $19(95.0)$ & $20(100.0)$ & $0.311^{*}$ \\
Excoriation & $16(80.0)$ & $19(95.0)$ & $0.342^{* *}$ \\
Crusting/Oozing & $5(25.0)$ & $8(40.0)$ & $0.311^{*}$ \\
\hline
\end{tabular}

*Chi-square test was done to measure the level of significance. ${ }^{* *}$ Fisher's Exact test was done to measure the level of significance. "Figure within parentheses indicates in percentage.

Table IV: Distribution of findings of dermatological examination

\begin{tabular}{lcc}
\hline \multicolumn{1}{c}{ Dermatological examination } & $\begin{array}{c}\text { No. of Pt. } \\
(\mathbf{n = 4 5 )}\end{array}$ & Percentage \\
\hline $\begin{array}{l}\text { Flexural lichemification or linearity } \\
\begin{array}{l}\text { Ichthyosis palmer hyperlinearity or } \\
\text { keratosiss pilaris }\end{array}\end{array}$ & 15 & 75 \\
$\begin{array}{l}\text { Tendency toward cutaneous } \\
\text { infection }\end{array}$ & 15 & 75 \\
$\begin{array}{l}\text { Tendency toward nonspecific hand } \\
\text { or foot eczema }\end{array}$ & 3 & 15 \\
Nipple eczema & 3 & 15 \\
Cheilitis & 7 & 35 \\
Recurrent conjunctivitis & 9 & 45
\end{tabular}




\begin{tabular}{lcc}
\hline Dannie-morgan infra orbital fold & 9 & 45 \\
Keratoconous & 5 & 25 \\
Orbital darkening & 2 & 10 \\
Facial pallor or facial erythema & 6 & 30 \\
Pityriasis alba & 10 & 50 \\
Anterior neck fold & 7 & 35 \\
Itch when sweating & 13 & 65 \\
Food intolerance & 4 & 20 \\
Course influenced environmental & 5 & 25 \\
\& emotional factor & 0 & .0 \\
White dermatographism or delayed & & \\
blanch & & \\
\hline
\end{tabular}

Table V: Distribution of patients by IgE level

\begin{tabular}{|c|c|c|c|}
\hline \multirow{2}{*}{ Investigations } & \multicolumn{2}{|c|}{ Study population } & \multirow{2}{*}{ p value } \\
\hline & Case (Group 1) & Control (Group 2) & \\
\hline . $\operatorname{IgE}$ & $601.30 \pm 423.18$ & $658.30 \pm 211.84$ & 0.593 \\
\hline
\end{tabular}

$*_{t}$ test was done to measure the level of significance. Data was shown as Mean $\pm \mathrm{SD}$.

Table VI: Distribution of patients by SCORAD index

\begin{tabular}{llll}
\hline \multirow{2}{*}{ SCORAD index } & \multicolumn{2}{c}{ Study population } & \multirow{2}{*}{ p value } \\
\cline { 2 - 3 } & Case (Group 1) & Control (Group 2) & \\
\hline $1^{\text {st }}$ visit & $49.76 \pm 17.25$ & $55.25 \pm 13.94$ & 0.275 \\
$\begin{array}{l}\text { Baseline) } \\
2^{\text {nd }} \text { visit }\end{array}$ & $27.39 \pm 11.16$ & $50.05 \pm 14.69$ & 0.001 \\
$3^{\text {rd }}$ visit & $12.08 \pm 6.87$ & $46.70 \pm 14.80$ & 0.001 \\
$\begin{array}{l}\text { Percent of } \\
\text { reduction from } \\
1^{\text {st }} \text { visit to 3 }\end{array}$ & $76.70 \pm 8.10$ & $16.88 \pm 8.70$ & 0.001 \\
visit & & & \\
\hline
\end{tabular}

*t test was done to measure the level of significance. Data were shown as Mean $\pm \mathrm{SD}$.

\section{Discussion}

In our study, at base line SCORAD index in case group was $49.76 \pm 17.25$ and in control group was $55.25 \pm 13.94$ ( $p>0.05$ ). At $2^{\text {nd }}$ visit that is at the end of 2 (two) weeks of medication SCORAD in case group (Mometasone) was $27.39 \pm 11.16$ and in control group (vaseline) was $50.05 \pm$ $14.69(\mathrm{p}=0.001)$ and at $3^{\text {rd }}$ visit that is at the end of 4 (four) weeks of medication in case group SCORAD was 12.08 \pm 6.87 and in control group was $46.70 \pm 14.80(\mathrm{p}=0.001)$. Percent of reduction of SCORAD from $1^{\text {st }}$ visit to $3^{\text {rd }}$ visit in case group (Mometasone) was $76.70 \pm 8.10$ and in control group (vaseline) was $16.88 \pm 8.70(\mathrm{p}=0.001)$ which indicates satisfactory improvement and statistically significant. Our study findings were consistent with study of Kapadia and Ghouri ${ }^{10}$ Chunharas et al ${ }^{11}$ Pei et al $^{12}$ Faergemann ${ }^{13}$ Vernon ${ }^{14}$

A study was conducted by Kapadia and Ghouri, to evaluate the therapeutic efficacy, safety and tolerability of mometasone furoate $0.1 \%$ preparation in childhood eczema. A total of 50 children, aged $>12$ years, with all types of childhood eczema were included in the study. Parents of children were instructed to apply a thin layer with gentle rubbing twice daily for three weeks. Tubes of mometasone furoate $0.1 \%$ cream, ointment and lotion were given to parents according to the need. Emollient was applied twice daily. Children were followed up at 3, $6 \& 12$ weeks. Out of 50 patients enrolled, at 3 weeks of follow-up only 43 reported. 29 (67\% showed improvement and $14(32 \%)$ fully resolved. At 6 weeks 32 $(74.4 \%)$ had complete resolution and $7(16.2 \%)$ had improved, but at 12 weeks only 25 patients $(58 \%)$ had resolved and 6 patients $(13.9 \%)$ relapsed, while 2 patients were gradually improving. Efficacy in resolution of sign/symptoms on 12 weeks was $(p<0.001)$. No cutaneous or systemic side effects were seen. They concluded that mometasone furoate $0.1 \%$ cream, ointment and lotion are found to be effective, safe and highly tolerable in childhood eczema and the compound was found equally safe in infants. ${ }^{10}$

A double blind multicenter placebo controlled study was conducted by Chunharas et al to assess the therapeutic efficacy of topical mometasone furoate 0.1 per cent cream in combination with loratadine syrup. Forty-eight patients, 23 boys and 25 girls, mean age 73.67 months, with atopic dermatitis were included in the study. The severity of the disease was measured by using the SCORAD index including the degree of erythema, dryness, edema/papulation, oozing/ crusting, lichenification, and excoriation. The degree of clinical signs and pruritic symptoms were graded. Mometasone furoate 0.1 per cent cream was applied to all patients once daily. One group received loratadine syrup and another group received placebo syrup. They were followedup on day 5,8 and 15. The severity of atopic dermatitis and pruritus significantly decreased after 14 days of treatment in both groups $(\mathrm{p}<0.001)$. There was no difference in therapeutic response between the loratadine and placebo groups $(p=0.99)$. All signs examined had decreased by the end of the study. The result demonstrated that 0.1 per cent mometasone therapy is very effective for treating childhood atopic dermatitis. ${ }^{11}$

Pei et al in their study looked the efficacy of two of the newer topical steroids $(0.1 \%$ mometasone furoate ointment and $0.005 \%$ fluticasone proprionate ointment) when applied under wet wrap dressings for the treatment of refractory atopic dermatitis in children. Forty children with moderate to severe disease were randomized to receive either one-tenth-strength diluted $0.1 \%$ mometasone furoate ointment or one-tenthstrength diluted $0.005 \%$ fluticasone proprionate ointment. These were applied once a day over a 4 -week period without wet wraps, or for 2 weeks without wet wraps followed by 2 weeks of application under wet wraps. There was a 2-week period for all patients when the topical treatment was standardized. At weekly follow-up, patients were assessed by a single blinded observer and objectively scored for disease extent and severity. A subjective score was also given for the impact of eczema on daily living. There was significant improvement in the disease severity from baseline during the first 2 weeks of the open application arm $(p=0.043)$, however, additional beneficial effects were limited after week 2 . Wet wraps further improved the disease severity and extent after week $2(\mathrm{p}<0.05)$, and were well tolerated. They concluded that both $0.1 \%$ mometasone furoate and $0.005 \%$ fluticasone proprionate ointments are effective in the treatment of atopic 
dermatitis, and that wet wraps are useful in further improving refractory disease in children. ${ }^{12}$

To study the antimicrobial effect in vitro of hexylene glycol and mometasone furoate fatty cream (contains $12 \%$ hexylene glycol) and to study the effect of mometasone furoate fatty cream on clinical parameters and microbial flora in patients with atopic dermatitis. Faergemann conducted study over twenty patients with moderate to severe atopic dermatitis were treated with mometasone furoate $0.1 \%$ fatty cream once daily for 3 weeks and then intermittently for 3 weeks. Quantitative culture for bacteria and fungi were taken at baseline, during treatment and 4 weeks after end of treatment. Both hexylene glycol and mometasone furoate fatty cream were effective in vitro against the studied microorganisms. Thirteen of 18 patients who returned for control were cleared after 3 weeks of treatment and $15 / 18$ patients or $83 \%$ were cleared after 6 weeks. Four weeks after end of treatment only one patient remained cleared. However, 11/14 patients who returned for this control were still improved compared to baseline. S. aureus was cultured in 16/20 patients at baseline but in only 7118 patients after 6 weeks of treatment. The number of S. aureus dropped significantly but increased twofold 4 weeks after end of treatment. The number of cultured P. ovale was also significantly reduced after 6 weeks. They concluded that the good effect of mometasone furoate fatty cream, which contains $12 \%$ hexylene glycol, in the treatment of atopic dermatitis paralleled by a significant reduction in the number of S. aureus and P. ovale. ${ }^{13}$. On the background of that study Faergemann et al conducted a study to study the effect and safety of prophylactic treatment with mometasone furoate fatty cream (contains hexylene glycol) for 6 months in patients with atopic dermatitis. Sixty-one of $68(90 \%)$ patients were still free of their disease after 6 months of twice weekly treatment and only one showed possible treatment related signs of skin atrophy. The number of Staphylococcus aureus and Pityrosporum ovale were significantly reduced in cleared patients. They concluded that mometasone furoate fatty cream is effective and safe both for treatment and as a prophylaxis in patients with atopic dermatitis. ${ }^{14}$

Vernon conducted a 6-week randomized, blinded study that compared mometasone furoate $0.1 \%$ cream, applied once daily, and hydrocortisone $1.0 \%$ cream, applied twice daily, in 48 children with moderate to severe atopic dermatitis. Mometasone furoate, a moderate-potency steroid, produced significantly greater improvement than the low-potency hydrocortisone used twice daily. The difference in therapeutic response was particularly evident in patients with involvement of more than $25 \%$ of their body surface area. Morning plasma cortisol levels were assessed before treatment, after 1 week of therapy, and at the end of the clinical trial. Plasma cortisol levels were transiently suppressed in one child who was treated with hydrocortisone and in none of the children treated with mometasone. ${ }^{15}$
In the light of findings of current study we can conclud that once daily application of $0.1 \%$ Mometasone furoate cream is effective in atopic dermatitis. Further large scale prospective study, comparing with any established standard therapy should be conducted in future.

\section{References}

1. Champion RH, Burton JL, Burns DA, Breathnach SM, In: Rook/Wilkinson/Ebling Textbook of Dermatology, $6^{\text {th }}$ edition, Blackwell science, $1998 ; 681-708$.

2. James WD, Berger TG, Elston DM, In: Andrew's Disease of the skin, Clinical Dermatology, $10^{\text {th }}$ edition, Canada: Saunders Elsevier; 2006;69-77.

3. Williams HC. Epidemiology of atopic dermatitis. Clin Exp Dermatol 2000;25:522-529.

4. Medansky RS, Brody NI, Kanof NB, Russo GJ, Peets EA. Clinical investigations of mometasone furoate: a novel nonfluorinated topical corticosteroid. Semin Dermatol 1987;6:94-100.

5. Correlae CE, Walker C, Murphy L and Craij TJ, Atopic Dermatitis: A Review of Diagnosis and Treatment. Am Fam Physician 1999;60:1191-210.

6. Hoybye S, Moller SB, De Cunha Bang F et al.Continuous and intermittent treatment of atopic dermatitis in adults with momethasone furoate versus hydrocortisone 17-butyrate.Cur Ther Res 1991;50: 67-72.

7. Rajka G, Avrach W, Gärtner L, Overgaard-Petersen H.Mometasone furoate $0.1 \%$ fatty cream once daily versus betamethasone valerate $0.1 \%$ cream twice daily in the treatment of patients with atopic and allergic contact dermatitis. Curr Ther Res 1993;54:23-29.

8. Lebwohl M, Peets E, Chen V. Limited application of mometasone furoate on the face and intertriginous areas: analysis of safety and efficacy. Int JDermatol 1993;32: 830-1.

9. Rafanelli A, Rafanelli S, Stanganelli I and Marchesi E. Mometasone furoate in the treatment of atopic dermatitis in children Journal of the European Academy of Dermatology \& Venereology 1999;2 :225-230.

10. Kapadia $\mathrm{N}$ and Ghouri S. Efficacy, safety and tolerability of mometasone furoate $0.1 \%$ cream, ointment and lotion in childhood eczema. Journal of Pakistan Association of Dermatologists 2008;18:93-96.

11. Chunharas A, Wisuthsare wong W, Wananukul S, Viravan S. Therapeutic efficacy and safety of loratadine syrup in childhood atopic dermatitis treated with mometasone furoate 0.1 per cent cream. J Med Assoc 
Thai $2002 ; 85: 482-7$.

12. Pei AY, Chan HH, Ho KM. The effectiveness of wet wrap dressings using $0.1 \%$ mometasone furoate and $0.005 \%$ fluticasone proprionate ointments in the treatment of moderate to severe atopic dermatitis in children. Pediatr Dermatol. 2001;18:343-8.

13. Faergemann J. A pilot study on the efficacy of mometasone furoate fatty cream on clinical parameters, time to relapse and microbial flora in atopic dermatitis. Journal of the European Academy of Dermatology and Venereology 2004;8 :217-221.

14. Faergemann J, Christensen O, Sjövall P, Johnsson A,
Hersle K, Nordin P et al. An open study of efficacy and safety of long-term treatment with mometasone furoate fatty cream in the treatment of adult patients with atopic dermatitis. Journal of the European Academy of Dermatology \& Venereology 2000;14:393-396

15. Vernon HJ, Comparison of mometasone furoate $0.1 \%$ cream and hydrocortisone $1.0 \%$ cream in the treatment of childhood atopic dermatitis. J Am Acad Dermatol 1991;24:603-7. 